Manuscript has been published online as Ahead of Print:

Accepted author manuscript version reprinted, by permission, from International Journal of Sport

Communication, 2019, https://doi.org/10.1123/ijsc.2018-0173. C Human Kinetics, Inc.

\title{
International Sport Federations' Social Media Communication: A Content Analysis of FIFA's Twitter Account
}

Mathieu Winand ${ }^{1}$, Matthew Belot ${ }^{2}$, Sebastian Merten , ${ }^{1}$, Dimitrios Kolyperas ${ }^{2}$

${ }^{1}$ LUNEX University, Luxembourg

${ }^{2}$ University of Stirling, United Kingdom

Final version available at https://journals.humankinetics.com/doi/abs/10.1123/ijsc.2018-0173

To cite this article:

Winand, M., Belot, M., Merten, S., \& Kolyperas, D. (2019). International Sport Federations'

Social Media Communication: A Content Analysis of FIFA's Twitter Account.

International Journal of Sport Communication, 12(2), 1-25 doi: 10.1123/ijsc.2018-0173

\begin{abstract}
This study aims to analyze the way in which Twitter is used by international sport federations to interact and engage with its followers. A content analysis of 5,389 online messages tweeted by FIFA using NVivo qualitative data analysis software was conducted between August 2014 to January 2015. Results suggest that FIFA does not use Twitter to its full potential by mainly sharing one-way information rather than engaging to a greater level with its followers. The research highlights the importance of the effective use of Twitter as a potential powerful communication tool for international sport federations, which are understood as metaorganizations whose members are organizations themselves. Communicating about social development and engaging followers, included their affiliated national sport associations, could potentially increase international sport federations' reputation and build trust amongst followers and stakeholders.
\end{abstract}

Keywords: engagement, football, meta-organizations, new media, relationship marketing

Winand and Merten are with the International Sport Management Dept., LUNEX International University of Health, Exercise and Sports, Differdange, Luxembourg. Belot is with the Faculty of Health Sciences and Sport, and Kolyperas, Stirling Management School, University of Stirling, Scotland. Belot is also with Bannatyne Health Club \& Spa, Aberdeen, Scotland.

Winand (mathieu.winand@lunex-university.net) is corresponding author. 
It has been widely accepted that social media plays a major role in society as it has become a worldwide trend (Campos, Anagnostopoulos, \& Chadwick, 2013). This also causes new challenges for sport organizations, as their main communication tasks developed from media relations and the provision of content for media representatives pertaining to tasks that were previously only performed by media companies (Nicholson, Kerr, \& Sherwood, 2015). Although academics have claimed there has not been enough research done in this area (O'Shea \& Alonso, 2011), there have been a growing number of studies within the field of social media and the influence it has within the sport industry (see Abeza, O'Reilly, Seguin, \& Nzindukiyimana, 2015, 2017; Filo, Lock, \& Karg, 2015). While some authors have focused on defining the reasons why individuals (including professional athletes) engage in social media (Hambrick, Simmons, Greenhalgh, \& Greenwell, 2010; Mahan, 2011; Meng, Stavros, \& Westberg, 2015; Witkemper, Lim, \& Waldburger, 2012), others have considered the impact of social media activity on sport brand association and management (Parganas, Anagnostopoulos, \& Chadwick, 2017; Wallace, Wilson, \& Miloch, 2011), and focused on understanding the different motives for virtual interaction in regards to fans and followers (Gillooly, Anagnostopoulos, \& Chadwick, 2017; Jordan, Upright, \& Forsythe, 2017; Stavros, Meng, Westberg, \& Farrelly, 2014).

In addition, a fresh stream of research has assessed the implementation of social media within sport teams' or sport organizations' strategies and their desired outcomes (Abeza, O’Reilly, \& Seguin, 2017; Abeza, O'Reilly, Seguin, \& Nzindukiyimana, 2017; Campos et al., 2013; Gibbs, O’Reilly, \& Brunette, 2014; Parganas, Anagnostopoulos, \& Chadwick, 2015; Williams \& Chinn, 2010). Within this context, Twitter has become a popular social media platform for multiple types of users such as athletes, teams and leagues across the globe to share a wide variety of content and enable followers to keep up to date with their favorite athletes and teams in the sport they are most interested in (Hambrick, 2012; Naraine \& Parent, 2016a). Researchers have increasingly become interested in studying the impact social media 
platforms such as Twitter can have toward building relationships between organizations and their stakeholders within the sport industry (Abeza, O’Reilly, \& Reid, 2013; Naraine \& Parent, 2016a; Parganas et al., 2015; Stavros et al., 2014; Williams \& Chinn, 2010; Witkemper et al., 2012). In sports, relationship marketing (RM) has become a key strategy employed by organizations in order to retain key customers and answer the different needs and wants of consumers. Witkemper et al. (2012) argued that RM strengthens brand awareness, enhances the understanding of consumer needs, increases loyalty and adds value for consumers.

Existing literature has mainly focused on professional sports teams and athletes' communication through social media (Gibbs et al., 2014; Hambrick et al., 2010; Meng et al., 2015; O'Shea \& Alonso, 2011), but has not yet addressed the way in which international sport federations (IFs) use social media to communicate. IFs are much different from sport teams or athletes, as they would not partake in sport competitions, but rather organize them and vouch for the rules of the game they promote (Zintz \& Winand, 2013). They therefore have a different agenda as compared to national or local teams and their athletes, and represent their organization's members (i.e., national sport federations). As such, they fall under the term of meta-organizations (Ahrne \& Brunsson, 2008) as their members are not individuals, but organizations themselves. Meta-organizations and their members are both autonomous, but by affiliation to a meta-organization, organization members renounce some of their autonomy which allows the former to make decisions affecting their members. This may have implications with regard to the way meta-organizations communicate and involve their stakeholders and their organizational members in their official communication. One of the most famous IFs is FIFA (Fédération Internationale de Football Association) which manages the game of football, and whose members are national football associations around the world.

The purpose of this research is to examine the way FIFA utilizes Twitter and to analyze how this IF interacts with its followers using this particular social media platform. 
This is the first known study that solely focuses on the social media communication of an international sport governing body. The study aims to contribute to the existing literature on sport communication and sport management by providing evidence as to how IFs communicate on social media, including discussions of the way they interact and engage with their followers. Compared to sport teams or athletes, IFs are less likely to have fans, but are likely to be noticed by fans of the particular sport the IF represents. The content of communication and way they communicate to their followers may significantly differ as IFs would not expect them to be passionate about their organization, but about the sport itself. Furthermore, their members are national association, not individuals. Therefore, it may be expected that IFs involves their organization members in their communication. This research will investigate how meta-organizations, which represent the interests of their organizational members, communicate and interact with social media followers, including the members themselves and the general public. This also includes analysis of what type of content is shared by FIFA through social media with followers on Twitter, and how FIFA engages with its followers. The authors also seek to provide a tentative explanation for why FIFA should share and interact with followers, leading to managerial implications on improving social media communication and propositions for future research directions.

\section{Literature Review}

\section{Social Media and Sport}

In 2017, 2.46 billion people used social media applications (Statista, 2018). As apps are available to all through devices including computer laptops, tablets or smartphones, the use of such media, as well as virtual communities on social media, keeps growing (Meng et al., 2015; Stavros et al., 2014). Williams and Chinn (2010) defined social media as "tools, platforms, and applications that enable consumers to connect, communicate, and collaborate with others" (p. 422). Social media provides platforms for co-creation, where the communication process is two-way and customers can become the actual marketers. 
According to Abeza, O'Reilly, and Reid (2013), users have the potential to create, listen, learn, participate, share interests, experiences, and commentary using collective writing. This enables users to become both "producers" and "distributors" of information on social media. Sport consumers are seen as "channels" through which the sport products can be promoted (O'Shea \& Alonso, 2011), and sports fans have come to be both the consumer and the product advocate. Mahan (2011) stated that digital social media platforms have developed into a point of emphasis in the sport industry as sport organizations, athletes, sponsors and media outlets are looking towards these new technologies in order to communicate quicker with the sport consumer while also delivering information about products or brands to (prospective) consumers. Filo, Lock, and Karg (2015) argued that "social media present a cost-effective medium that: embraces interactivity, collaboration and co-creation above one-to-many communication; integrates communication and distribution channels; provides opportunities for customization; and delivers superior speed to the delivery of information communication and feedback" (p. 167).

In the sport industry, social media offers a number of opportunities to sport organizations as well as sport managers and marketers alike. Most importantly, social media outlets are a vehicle to develop the level of commitment and engagement of followers through the creation of innovative and interactive experiences, while also increasing relationships which can be beneficial considering the highly competitive environment in which sport organizations operate and reside (Meng et al., 2015). A study by Winand, Scheerder, Vos, and Zintz (2016) showed that half of sport federations surveyed in Belgium innovated by introducing new online services to answer members' needs and communicate with them, while these federations perceived competitive pressure from other organizations to attract members and resources (Winand, Vos, Zintz, \& Scheerder, 2013).

The value of engaging in social media communication to build relationships with fans and members has also been identified as part of the community sport context by Jordan, 
Upright, and Forsythe (2017). Mahan (2011) argued that sport organizations, sponsors and media organizations, defined as "traditional producers", have acknowledged the prominence that can be generated by utilizing such new media platforms such as Twitter in order to achieve marketing objectives. Created in 2006, Twitter has been described as a microblogging site (Campos et al., 2013; Hambrick, 2012; Smith, Fischer, \& Youngjian, 2012; Witkemper et al., 2012) where users post what are known as 'tweets' limited to 280 characters. These short updates are an example of user-generated content which makes Twitter part of social media (Campos et al., 2013).

Whether individuals or organizations, Twitter provides organizations and individuals the possibility to create their own personal home page where they can post tweets which gives free subscribing users the ability to read and follow them on a daily basis (Hambrick, 2012). Twitter users are able to 'retweet', explained as a reposting of another user's tweet (Campos et al., 2013), 'reply', comment or 'favorite' tweets within their continuous news feed by the followed users. In turn, this enables effective information sharing within the Twitter community as it expands from one user to the other in a matter of seconds (Hambrick, 2012; Hambrick et al., 2010). Ultimately, this simplifies the communication processes with placeless interaction which have helped create relationships between consumers and (sporting) organizations that would have not been achievable in the past (Meng et al., 2015). Two other interesting features of Twitter include the use of hashtags, that is the "\#” character followed by any series of characters or word(s) to relate a tweet to a topical category, and the use of “@” followed by a Twitter account name, enabling anyone to address a tweet to any Twitter user. The motivations behind the use of Twitter, however, vary depending on users' different needs. Athletes, sport organizations and professional teams all have different desired outcomes of using such platforms to interact with their followers.

For instance, through analyzing American professional sport teams Twitter communication, Abeza, O'Reilly, Seguin, and Nzindukiyimana (2017) showed that Twitter is 
used as an RM tool to create value for fans through two-way dialogue enhancing fans' connections with their teams. Social media is a tool that is "making the RM approach much more practical, affordable, and meaningful” (p. 353). In 2016, Twitter further expanded its business into live streaming video of various events or pre-events including sport content with broadcasting contracts with Major League Baseball, National Hockey League (Forbes, 2017), National Football League (NFL Media, 2016) and the Professional Golfers' Association Tour (PGA Tour, 2017). Considering the important role of the NFL in the global sport business, this major step may be seen as trendsetting for other sports federations. The relatively low rights sum of $\$ 10$ million that has been reported could also be seen as an investment in new markets with the aim of increasing reach (López-González, Stavros, \& Smith, 2017).

\section{Motivation and Understanding Behind the Use of Twitter}

Professional athletes' use of Twitter. Twitter has become a prevalent social network amongst professional athletes attempting to reach out to their fans (Frederick, Lim, Clavio, Pedersen, \& Burch, 2014). It has enabled athletes to communicate with fans in a more direct and open way compared with the previous modes including going through the public relations department of sports organizations and other mainstream media outlets (Hambrick et al., 2010). The study conducted by Hambrick et al. (2010) examined the ways in which professional athletes used Twitter by undertaking a content analysis of athletes' tweets to understand the communication interactions between them and their fans. The authors placed each collected tweet in one of six themes ranging from 'interactivity', 'diversion', 'information sharing', 'content', 'promotional', and 'fanship'. In order to gain a general understanding of how communication occurs between fans and athletes, the authors used what is known in the communication research area as the 'Uses and Gratifications Theory' (UGT) which focuses primarily on how consumers engage within a variety of activities and their reasons for doing so. 
UGT can be employed toward online social media sites such as Twitter, and may help scholars to understand their continuous growth. Hambrick et al. (2010)'s results showed that interactivity was the most common motive with $34 \%$ of tweets collected falling into this theme, indicating that athletes used Twitter to directly interact with their fans (followers) and those with the most followers had more engaging tweets. Twenty-eight percent of tweets were seen as 'diversion' tweets as they comprised mainly of non-sport-related subjects whereas $15 \%$ of their tweets were implicated in 'information sharing' on their own team or sport(s) and finally $5 \%$ of their tweets included 'promotional' topics which, according to the authors, indicated that athletes did not take advantage of the power of Twitter to promote their endorsements, sports and team. It is the power of new technologies such as Twitter which provides new opportunities for athletes to communicate with sports fans and has ultimately changed the way in which people communicate (Hambrick et al., 2010), but also how athletes brand themselves and what image they present on social media image (Lebel \& Danylchuk, 2014).

Professional team sports' use of Twitter. According to O'Shea and Alonso (2011), professional sport teams are highly affected by the rapid change in new technologies. Due to fierce competition, shifting external pressures and high demands from sport club fans and other stakeholders, professional sport team managers are heavily influenced in ways to market and brand their product. Most professional sports teams have access to social media to stay close and connected with their fans. In order to do so, they have used Twitter to share breaking news, pictures, videos, advanced access such as live updates during games or special events for example (Gibbs et al., 2014). According to Cleland (2010) a strategy change was made to improve the relationship with the fans. Social media enabled clubs to turn a one-way into a two-way dialogue (MacIntosh, Abeza, \& Lee, 2017), leading to potential sustainable relationships with fans and long-term financial implications. Gibbs et al. (2014) investigated "how professional sport teams reach, inform and satisfy fans" (p.189). By combining semi- 
structured interviews and an online survey, they aimed to understand what motivates and satisfies Twitter followers of professional sports teams using the Canadian Football League and its eight teams as their main participants. Similarly to Hambrick et al.'s (2010) study, the authors used UGT to underpin their study whereby they argued that it assumed users are typically active and choose their media sources based on the influence of satisfactory social and psychological needs (Gibbs et al., 2014). The authors found four key gratifications pursued by Twitter users such as interaction, promotion, live game updates, and news which add to the understanding of how professional sport teams can successfully develop strategic fan engagement in an effective and efficient manner.

Pritchard, Stinson, and Patton (2010) introduced two psychological aspects regarding team identification: affinity and affiliation. They explained affinity as a process whereby fans associate and identify themselves to a team, because there are similarities between the fan and the team in particular ways. Affiliation is described as the will for a fan to be a part of a particular group. It demonstrates the level to which a fan adopts particular characteristics or perceptions of a sport organization. The study examines the dual relationship between both psychological aspects of team identification being influenced by a team's positive features (which creates affinity). Accordingly, communicating core organizational ideals (which builds affiliation) should not just arouse identification but also increase the attendance to the team's events. In terms of Twitter, associating affinity and affiliation from fans to the sport organization would increase the number of followers whilst also increasing the identification to it. In a study by MacIntosh et al. (2017) examining a National Hockey League team, the authors suggested sports teams should interact with their followers to increase fans commitment which is related to the time fans spent reading tweets and engaging with other fans.

Sport organizations' use of Twitter. Campos et al. (2013) argued that "exploiting Twitter's two-way communication capabilities has been identified as a key to building 
relationships and the most suitable way to conduct strategic communication campaigns on Twitter" (p.6). Hence engaging with fans or followers is crucial for sport organizations who want to exploit the functions of Twitter in more depth. As they seek to please their fans, the latter are influenced to use Twitter repeatedly which generates more openings to venture the social media application for sport organizations (Campos et al., 2013). Furthermore, in previous studies it has been suggested that creating content brings engagement as new consumers expect to have online services and information supplied in an eloquent, targeted, and manageable manner that is available for immediate consumption (Campos et al., 2013). Hambrick et al. (2010) argued that sport organizations typically use Twitter to share information on games, ticket sales, and to increase brand awareness and product sales. To use Twitter effectively and efficiently, sport organizations must fully understand its features and the potential effects that may benefit these organizations (Hambrick et al., 2010). This is supported by Sutton, McDonald, Milne, and Cimperman (1997), who stressed the importance of delivering and answering fans' expectations in terms of sharing valuable content which will, if used effectively, result in mutual benefits including personal connectedness for the fans/followers, and an increase in the sport organization's image in the consumers' minds.

Meng et al. (2015) provided brighter visions of the use of social media in sport and especially regarding sports organizations' use of social media to communicate and engage with fans. Qualitative data research was conducted and content analysis was undertaken to examine the online 'messages' posted by 30 NBA franchises on Facebook and Twitter. The findings of this study showed that the latter have taken great advantage of social media platforms. Meng et al. (2015) developed a framework of team communication through social media, highlighting four communication sets: Informing, Marketing, Personalizing, and Activating. The authors recommended that sport organizations should make rigorous efforts in their communications strategy by implementing these four types of communication. Results showed that Informing and Marketing communications were a one-way dialogue whereas 
Personalizing and Activating were a two-way dialogue, which offered more interaction with fans. Within these four themes there are a number of different activities in which teams take part in and use social media to communicate these activities. These are: "Organizational news", "Activities outside sport" and "Diverting fans to other content" (Informing); "Promoting" and "Direct sales" (Marketing); "Initiating contact" and "Direct responses" (Personalizing); "Group Involvement" and "Gathering feedback” (Activating). All of these forms of communication can help sport organizations achieve their marketing goals, strengthen relationships and retain customers. However the authors stated that not every team used Twitter as efficiently as the other. Indeed "some teams' online presence appeared forced and unnatural" and that "the social aspect of these platforms was underutilized with a large proportion of posts focused on traditional one-way communication, rather than engaging fans through more interactive communication" (Meng et al., 2015, p. 205, 207).

\section{Relationship Marketing, Social Media and Sport}

Numerous researchers have conducted studies on Relationship Marketing and how it affects social media users' motivations, whether they are individuals (fans and/or followers) or sport organizations. The use of such social media platforms such as Twitter can prove to be very beneficial in building meaningful relationships between both parties (Abeza et al., 2013), with organizations gradually moving forward from simply creating a one-way communication to a two-way communication scheme in order to build long-term relationships with their customers. Likewise, Gillooly, Anagnostopoulos, and Chadwick (2017) used Uses and Gratifications to analyze the use of social media in sponsorship activation campaigns at London 2012 Olympic and Paralympics Games. They suggested Twitter is a way for sponsors to engage in dialogue with their target audience while also developing close relationships with that audience. This is the overall benefit of adopting a RM strategy, as it is crucial for organizations to be able to retain customers. In order to achieve this, a clear knowledge of customers' needs and wants is necessary, as they have become more and more suspicious of 
sport organizations' marketing objectives. Therefore, it is important that organizations seek to make sure the interaction between them and their followers is equally beneficial (Stavros et al., 2014).

Parganas et al. (2015) analyzed how Liverpool Football Club uses Twitter to manage its brand. They showed that the club used Twitter to both communicate about product-related and non-product related brand attributes. Product-related ideas, linked to the game itself, players, team success and manager were more tweeted and created more responses. However, the growing public/fan expectation is for teams to provide more behind-the-scenes moments in addition to game-related content (Abeza, O'Reilly, \& Seguin, 2017). The real-time feature of Twitter seemed particularly relevant for sport marketers who can use it has a tool to manage brand perception in real time (Wallace, Wilson, \& Milch, 2011) as well as providing the opportunity for fans to engage with their club (Bruhn, Schoenmueller, \& Schaefer, 2012), and hence develop their RM (Abeza, O’Reilly, \& Seguin, 2017).

Abeza, O’Reilly, and Seguin (2017) showed how social media can provide an opportunity for sport teams to humanize their brand, and to get away from the image of commercial organizations not caring about their fans. Abeza et al. (2013) also explored the different opportunities and challenges sport managers faced by using social media in their RM strategy. The authors qualitative data case studies on eight sport organizations who organized running events in Canada. Their results showed that all organizations used social media platforms to achieve their RM goals. Some of the opportunities to use social media that were found included: better knowledge of customers, advanced customer-organization interaction, effective sport participants and fans engagement and efficient resource management (time and money).

However, some of the challenges that were found also should be considered as they can lead to a lack of control over posted messages, concerns over the credibility and reliability of information, concerns over the effectiveness of messages in reaching end users, difficulties 
in identifying "true" online customers and setbacks with the allocation of organizational resources (Abeza et al., 2013). In a similar study, Williams and Chinn (2010) examined how sport organizations could reach their RM goals through social media. They argued that the new challenge for sport organizations is how to handle the shift in customer relationship, as consumers now are known as "prosumers" due to their ever-growing knowledge. The authors devised an improved framework based on Grönroos's (2004) RM model which focused on communication, interaction and values in order to include 'prosumers' and describe the different interactions that take place through social media communications.

Williams and Chinn's (2010) model recognizes the strategic value of social media in the RM process through two-way communication and discusses prosumers' needs of direct conversations with sport organizations. Their study was based on providing more insight for sport marketers to meet their RM objectives through analyzing the different values of each social media platform, and how organizations have used social networks for promotion strategies and to informally interact with fans/followers. In regard to the integration of Twitter to meet RM goals, the study found that the use of such social media outlet has proven to be effective in strengthening and maintaining relationships with fans as it provides sports organizations, coaches and athletes the opportunity to instantly communicate with their followers. In turn, this allows fans to gradually interact and add value to their sporting interests. However, truly using social media platforms for relationship marking and engaging with followers, fans or consumers requires users to overcome key challenges that have been identified by Abeza, O’Reilly, and Seguin (2017), categorized into management, stakeholders and data related challenges.

\section{Twitter and National Sport Organizations}

Campos et al.'s (2013) research consisted of analyzing the integration of social media platforms, in this case Twitter, into National Sport Organizations (NSOs) to assess the ways in which sporting organizations' social media content enables them to reach their overall 
strategic objectives in terms of engagement and persuasion. This study analyzed how nine NSOs for different sports in England used Twitter as the degree of integration into the strategic operations of sport organizations such as NSOs has not been given much focus. The results of this study showed that the NSOs engage through Twitter effectively even though some were more efficient than others. For example, England Hockey found a better engagement with their followers than others due to the fact they had more followers (Campos et al., 2013). However, some NSOs were able to generate higher levels of engagement despite not having a significant number of followers. According to the authors, this might have been due to the popularity of the sport (etiquette) and the content shared. The focus of the nine NSOs differed, as some were more focused on engaging with their followers and others were more focused on increasing participation through Twitter. More recently, Naraine and Parent (2016b, 2017) showed that Canadian national sport organizations use Twitter to promote, report and inform their multiple stakeholders, but they failed to realize the strategic value of such medium. Lack of capacity and external pressures exerted on Canadian national sport organizations explained why they tend to use social media in a similar manner.

While previous research has focused on and analyzed social media communication by players, managers, clubs and national associations (Abeza, O’Reilly, \& Seguin, 2017; Abeza, O’Reilly, Seguin, \& Nzindukiyimana, 2017; Meng, Stavros, \& Westberg, 2015; Naraine \& Parent, 2016a, 2017; Parganas et al., 2015), to the authors' knowledge no research has yet investigated how international sport organizations communicate on social media platforms. These organizations act globally and social media should be seen as a way to target a large and worldwide audience that fits their purpose and would reach out to their multiple stakeholders (Naraine \& Parent, 2016b). Furthermore, contrary to the other organizations mentioned above (except to some extent national sport organizations), these international organizations are considered meta-organizations (Ahrne \& Brunsson, 2008; Malcourant, Vas, \& Zintz, 2015), and have as primary members other autonomous organizations. The present 
research, therefore, investigates from the point of view of IFs, what content they communicate on Twitter and whether and how they interact with their followers. This study contributes to better understanding social media use and particularly what and how meta-organizations communicate to their followers on social media.

\section{Method}

A qualitative data analysis was conducted to investigate the way IFs use Twitter and how they interact with their followers. A case study-based analysis was chosen to investigate, in details, situations or events where researchers have no control over and they aim at developing or extending new theoretical concepts (Yin, 2003).

\section{Case Study: FIFA}

FIFA has become one of the most recognizable IFs in the world, most notably due to the ever-growing popularity of football across all continents. Founded in 1904, FIFA has 211 member associations and employs more than 400 people (FIFA, 2018a). Following recent reforms, FIFA statutes (FIFA, 2016) detail that its governance structure is constituted of a Congress (supreme and legislative body) assembling the 211 member associations, and a Council (strategic and oversight body), composed of 37 elected members, including the President who is elected by the Congress. The executive and administrative body of FIFA is the General Secretariat, and Committees advise and assist the Council.

FIFA aims to develop the game of football worldwide, organize international tournaments, and promote the impact football can have in society (FIFA, 2018a). In terms of marketing, FIFA aspires to position itself as "best in class in the sports marketing and sponsorship field" (FIFA, 2018a). FIFA's marketing is oriented towards promoting and adding value at events for sponsors, host nations and cities, member associations, sponsors and football fans. FIFA also aims to ensure "a consistent and aspirational brand image” (FIFA, 2018a).

FIFA joined Twitter in May 2010. Its main account (@FIFAcom) contains of the latest football news from around the world. It has more than 11.9 million followers (March 2018) 
and has produced more than 70,000 tweets. The second account involved in this study (@)fifamedia) is the FIFA Media department which is based at the FIFA headquarters in Zurich, Switzerland. It is responsible for handling media communication and operations for FIFA, which was created in April 2011. It has more than 250,000 followers (March 2018) and has created more than 7,000 tweets.

\section{Data Collection}

The preliminary stage of this study consisted of collecting all the tweets that were posted by@FIFAcom and @fifamediaan between August 21, 2014 and January 21, 2015. The time period was chosen to begin after the 2014 FIFA Men's World Cup, which attracts the most social media attention out of football's major international competitions. This time period also overlapped with the FIFA U-20 Women's World Cup (Canada, August 5-24) and FIFA Club World Cup (Morocco, December 10-20 December). It was a deliberate choice to focus on communication that took place after the main FIFA World Cup tournament in order to analyze FIFA communication on its activities, and not on football game results.

@FIFAcom is focused on general football news, whereas @ fifamedia focuses on internal and external news pertaining to FIFA's diverse activities through the sport of football. Tweets where collected over five months in order to have a large selection of tweets and help develop a better representation of FIFA's social media use (Meng et al., 2015). A total of 5,389 tweets posted on both accounts were collected through the add-on NCapture and imported into QSR NVivo 10 qualitative data analysis computer software to observe how the international governing body for football used this social media platform to engage, interact and communicate with football fans across the globe.

\section{Data Analysis}

A thematic content analysis of the 5,389 tweets was carried out using QSR NVivo 10 software. Meng et al.’s (2015) framework of four types of social media communication (i.e., Informing, Marketing, Personalizing and Activating) has been used as the generic thematic 
structure for the present analysis. Each tweet was manually coded within one or more themes with the support of the software to keep track of all the tweets and the detailed thematic structure that emerged. Sub-themes were used in line with Meng et al.'s (2015) framework, and further themes were created to report FIFA's particular communication, and the manner in which it interacts and engages with followers. Coverage has been calculated for each theme as the percentage of tweets in the theme from the 5,389 tweets that have been analyzed during the five months period, and for each sub-theme as the percentage of tweets in the sub-theme from the total number of tweets in its theme.

\section{Results}

From the months of August 2014 until January 2015, FIFA was particularly active on Twitter. The examination of the governing body's posts exposed many different topics not only within the four main communication themes, but also within the different activities included in those types of communication. Furthermore, some of FIFA's tweets were found to fit in more than one communication theme as well as in more than one activity. The coverage of FIFA's Twitter activity is presented first here, then FIFA's Twitter communication is analyzed by themes.

[Insert Table 1 about here]

\section{Coverage of FIFA's Twitter Activity}

The number of tweets within each of the four communication themes and sub- themes is outlined in table 1 . FIFA communicates primarily in a one-way stream given $89.33 \%$ of its tweets during the four-month period of analysis were categorized as "Informing." Marketingoriented tweets represented $9.67 \%$ of all tweets. In terms of the two-way communication stream. FIFA activates followers in $8.96 \%$ of its tweets, and personalized tweets represent $1.06 \%$ of tweets. The total theme coverage is greater than $100 \%$ given some tweets were classified in more than theme. A good example of this would be when FIFA attempts to promote one of their events, such as the Club World Cup, through marketing communication. 
This can also be included in personalizing communication as FIFA askes football fans if they have purchased their tickets for their teams upcoming games during this event (“@Moghreb_Tetouan fans, watch your team on the biggest stage! \#ClubWC tickets here: (Link provided)").

Among the tweets analyzed, 2,494 (46.3 percent) used a hashtag. The top five most popular hashtags are \#clubwc (n=266), \#ballondor (n=263), \#worldcup (n=207), \#ucl (n=125) and \#wwc $(\mathrm{n}=111)$. Hashtags are frequently used by FIFA to draw attention to particular events taking place such as the FIFA Club World Cup, the election of the FIFA Ballon d'or award or the UEFA Champions League competition. These events are related to different types of communication themes. The findings relative to FIFA's social media use and the way in which it communicates on Twitter, are considered in the following sections.

\section{FIFA's Twitter Communication Content and Followers' Engagement}

Table 2 shows FIFA Twitter communication by themes illustrated through examples of tweets. FIFA informed its followers and promoted itself, and also attempted, to some extent, to activate and personalize its communication, directly or indirectly, with individual followers which would help getting them involved within a global community through the sport of football.

[Insert Table 2 about here]

"Informing" relates to providing information on different topics such as "Activities outside sport", "Diversion”, "Organizational news" and "Stakeholder news" (Meng et al., 2015). The first theme referred to information related to players, members of staff, or the sport organization taking part in non-sport activities associated with football. The different activities found throughout the data analysis are as such: charity ("FIFA to invest USD 1.5 million \#WorldCup public viewing revenue in Football for Hope"), employment ("Want to work for FIFA? We have 2 video journalist vacancies in \#Digital department. Apply here: (Link provided)"), health ("FIFA has launched a mental health research project to try to lift 
the taboos surrounding it”), social media ("Keep track of FIFA's Social Media activity across Twitter, Facebook and YouTube right here! (Link provided)"), worldwide issues ("TOGETHER \#WECANBEATEBOLA: Learn about FIFA's public health campaign in the fight against Ebola. (Link provided)"), and personal information ("Happy birthday to RogerioCeni (42), FrankLeboeuf (47) \& @Mad7e7 (38)"). The latter, concerned with providing information on players and staff that are part of the footballing world was the most tweeted about with $65.5 \%$ coverage within "Activities outside sport".

"Diversion" refers to directing followers to other content such as pictures, videos, blogs or websites, match reports, interviews and stats on different players, managers and staff (Hambrick et al., 2010; Meng et al., 2015). Due to the, at the time of data collection,140 characters limitation on Twitter, followers would be linked to other websites for additional information that would be of interest to them ("WATCH:Video interviewwith@Cristiano on his latest FIFA \#BallondOr win. (Link provided)").

Organizational news comprised of news and information directly associated with the organization in relation to the sport of football. Three main sub-themes resulted from the data such as: Events ("Road to the 2018 \#WorldCup begins today in Miami."); Organization which includes subjects such as economy, finance, legal, technological, governance and ethical issues (“RT@jeromevalcke: FIFA committed to developing women's football in Brazil, with $\$ 15$ m investment pledge, a start.”); and Sport development including important subjects such as legacy and sustainability plans (“Brazil gets behind women's football development.").

Stakeholder news comprises news and information directly associated with players (“@LacazetteAlex kept up us his goal streak, while Lucas Barrios hit a hat-trick in @Ligue1.”), managers (“@MrAncelotti says @realmadriden's \#CopaDelRey exit could help their@LaLiga campaign.”) and member of staff at FIFA (“RT@SeppBlatter: Congratulations@Socceroos.The@afcasiancup hosts got off to a winning start: 4-1 v @ KuwaitFA in Melbourne. \#AC2015."), whilst also providing news and information on clubs, 
national teams and international leagues in relation to the sport of football ("Australia face Chinaas@afcasiancup knockoutstagebegins@Socceroos@theKFA@UzbekistanFF.”; “San Lorenzo see off Boca \#argentina.”).

"Marketing" communication arises when FIFA posted appropriate and engaging promotions and advertisements through two types of activities (Abeza et al., 2013; Meng et al., 2015): direct sales, which involved directly providing football fans with the opportunity to easily buy products online such as tickets and official merchandise on the FIFA Store ("Did you get an itchy sweater again? Get what you really want at the Official FIFA Online Store"; “@SanLorenzo fans, think your club can lift another trophy in December? \#ClubWC tickets here: (Link provided)"), and other marketing activities involving promoting competitions (“Road to the 2018 \#WorldCup begins today in Miami”), special events (“ONE HOUR TO GO: Just an hour until the ceremony begins. Follow our Live Blog here: (Link provided) \#BallondOr"), live games from leagues and international games all around the world ("LIVE: Follow Equatorial Guinea v Burkina Faso in Group A of the \#AFCON2015 here: (Link provided)"). But also upcoming league, domestic cup, Champions League fixtures from different continents (for example UEFA; AFC; Copa Libertadores) and international games (“@FCBarcelona and@realmadriden face difficult away games@LaLiga.The weekend previewed: (Link provided)").

"Activating" means of communication focusses on creating ways in which online followers would get involved as much as possible in different activities (Meng et al., 2015) such as: gathering feedback from followers /football fans in order to collect their opinions before developing or implementing a new idea; and group involvement ensuring, where possible, followers/football fans are included in relevant general interactive processes including group discussions and group-focused questions such as ("QUESTION: With \#AFCON2015 now underway, we want to know who your favourite African player of all time is \& why?). Gathering feedback from followers and football fans only occurred once. Indeed 
there was only one retweet by @FIFAcom from @FIFAWWC asking for football fans’ opinions ("RT@FIFAWWC: YOURVIEW: \#U20WWC is over; but YOUR participation is not! How can we improve our content? We'd love your feedback.").

"Personalizing" communication consisted of conversing with individual followers (Gillooly et al., 2017; Stavros et al., 2014). In this case these could be either followers/football fans or sport people, mainly football players. This type of communication could be done in two ways: through direct responses which involved openly responding to individual questions or comments by either tweeting or retweeting a follower's response (“ $R T$ @PetrCech:@FIFAcom yes, of course :-)”; “RT@acciesfc: @FIFAcom Many thanks FIFA, recognising our great run!'). The other way is by initiating contact which consisted of direct, interpersonal contact with an individual fan or a follower, initiated by FIFA (“@Simeone answered your question @,Ahmed_Osaimi! See his reply in our Live Blog: (Link provided)”.

Twitter has allowed FIFA to strengthen its level of interaction with football fans and followers however it is clear that the level of communication with its followers is not as engaging and interactive as it could be. The next section details the coverage of FIFA's tweets according to the different themes.

\section{Discussion}

Twitter is referred as a communication tool with potential to enhance team identification (Meng et al., 2015) and RM (Abeza et al., 2013; Williams \& Chinn, 2010). However, it is different for international sport federations (IFs) as they represent the sport in which teams play and they vouch for the rules of the sport they promote (Zintz \& Winand, 2013). While a sport team or player is considered to have a fanbase, this is less obvious with international sporting bodies. IFs operate at a much higher scale than a sports team, and are accountable to a number of different stakeholders, including their member organizations. In this case, IFs would raise the interest of specific sport fans who are interested in learning about the development of the sport. They would not identify with the international body itself 
like they would for their favorite team, but their interest for the sport would have led them to follow the social media communication of its overarching body. This body, FIFA in this instance with regards to football, is interested in its own reach through social media, as reflected by digital data analytics during World Cup football (FIFA, 2018b).

These findings reveal the different types of content shared and tweeted by FIFA: (1) sharing news and information both in and out of the sport of football,(2) sharing entertaining content with links provided to the main website, (3) using promotion, sales and advertising for events organized by FIFA but also football games all across the world from league games to international games, (4) questions directed to football fans, (5) interacting with individuals or a group of fans/followers.

Waters and Jamal (2011) argued that non-profit organizations primarily use Twitter to deliver one-way communication. In line with the authors' findings, the current study found that most of FIFA's tweets directed its followers to a range of different information on its website. Twitter is essentially being used by FIFA as a channel to provide information which involves FIFA sharing details on specific events such as the World Cup and to generate a discussion from followers which ultimately could lead to an increase of interest for the event as suggested by researchers (Meng et al., 2015; Pritchard et al., 2010). FIFA's Relationship Marketing through social media seems limited to making its followers aware of footballrelated events taking place, but does not focus on other aspects of RM underlined by Witkemper et al. (2012) such as understanding consumer needs, increasing their loyalty and adding value for consumers. A majority of FIFA's communication is about sharing news from its main stakeholders that are national football associations, national teams, football clubs and players. This is in line with its structure of meta-organization to share news from its members, and also goes beyond by sharing information of the members of their members, for instance clubs within national football associations. 
Although Twitter has the potential to boost visibility and fan/follower knowledge as well as also strengthen the relationship between a sport organization and its global group of followers (Abeza, O’Reilly, Seguin, \& Nzindukiyimana, 2017; O'Shea \& Alonso, 2011; Waters \& Jamal, 2011; Witkemper et al., 2012), FIFA primarily uses Twitter to share information. FIFA does not capitalize on the opportunities that Twitter would give to build relationships with fans/followers and enhance its image as part of its communication strategy. Abeza, O'Reilly, and Seguin (2017) showed Twitter can be used to humanize a sport organization's brand and moving away from the negative image of a commercial organization. FIFA does not seem to embrace this potential and lacks the potential use in terms of two-way communication. On the other hand, Lovejoy, Waters, and Saxton (2012) argued there have not been enough indications that Twitter can accurately bring both shortterm and long-term financial advantages or build relationships between followers and organizations. Therefore, FIFA might be less motivated to put in the effort in terms of time and resources in order to build relationships with their followers. This could explain why FIFA uses more traditional one-way communication to share information on a number of different topics and promoting its activities rather than two-way communications.

Engaging football fans/followers would enable FIFA to achieve its goals in giving the game of football and the organization itself a cleaner image worldwide. The reason behind the lack of engagement with fans/follower in social media might be due to the high number of followers which make it difficult for sport organizations, especially IFs, to respond directly to individual fans and why these organizations tend to just share information. Even though this is understandable, there is an inevitable risk in not directly responding to football fans as it can cause confusion and annoyance from the latter towards the nature of this approach (Stavros et al., 2014). In keeping with Meng et al. (2015) results suggest FIFA could potentially interact more with football fans. Given that most of FIFA's tweets have external links provided to redirect fans to FIFA's main website, the organization could use some of its resources and 
enroll representatives to create an internal social network. This would give FIFA the opportunity to improve the communication with football fans and might enable the organization to keep control over its presence, commercial links and tasks. Although, as McLean and Wainwright (2009) argued, there is a risk in using such approach as it could push football fans away if FIFA over-commercialize their website. Additionally, there is also a risk for FIFA in revealing too much about what goes on behind the scenes. Considering the occurrences of recent years, fans/followers could use Twitter to respond negatively towards FIFA's ideas and intentions, especially following the 2015 global FIFA scandals over allegations of misgovernance and corruption (BBC News, 2015). This also raises the question whether the risk for FIFA to interact with football fans is potentially outweighing the benefits. As a meta-organization, FIFA members are organizations, i.e., national football association. FIFA may not particularly see the necessity to interact with individual football fans, but may be more interested in doing so with their members, although results did not show such behavior. The incentives for FIFA to openly communicate and interact with individual football fans could be an interesting research as to why meta-organizations interact with individuals. One of these incentives for FIFA to (increasingly) communicate to football fans can be found in an argument developed by Purdue (2001) on social capital involving trustworthy relationships between communities and leading organizations. In this sense, FIFA could be viewed as a social entrepreneurial organization, as the author describes this status as being similar to "transformational leaders" which combines business skills with a vision for the community as opposed to "transactional leaders" who focus on interacting with their followers. As a social entrepreneurial organization, FIFA contributes to successfully developing the football community. In line with Purdue (2001), this study shows that FIFA does share information on its activities in order to develop the game of football, for example “RT@jeromevalcke: Development seminars focus on FIFA's reforms as well as their impact on football's governance \& development globally - (Link provided)", but should focus on 
interacting with its followers more often as this would create greater awareness that FIFA is highly committed to developing communities through football. Furthermore, as argued by MacIntosh et al. (2017) with regard to fans commitment with their team and time spent reading and interacting with others on social media, FIFA interactions with football fans may potentially lead to strengthening its football community base.

However, there is some degree of conflict over trust between people and organizations in both partnerships and communities, as there could be constraints in producing social capital (Purdue, 2001). Results suggest that FIFA does not seem to communicate these types of content very often, which might be due to the lack of opportunity there could be in accumulating social capital. In line with Persson (2011), "good governance" could also lead to building trust between sport governing bodies and their communities. Indeed, incorporating good governance principles such as transparency, accountability, responsibility, equity, efficiency, and effectiveness whist also focusing on CSR activities and social capital, could enable sport governing bodies to reinforce their reputation and building trust within its community. During the period of data collection, FIFA, and particularly its president at the time Sepp Blatter, were under high public scrutiny over accusation of poor governance and corruption, which has led to the 2015 FIFA scandals. FIFA may have purposefully reoriented their social media communication to its stakeholders and chosen to reduce interaction with football fans to avoid negative outcomes. FIFA has a long journey in rebuilding trust with its stakeholders. Twitter represents a valuable tool for FIFA to do so, and its corporate social responsibility activities may be the right message to regain trust and improve its reputation such as the following tweet integrating governance and CSR activities: "Governance principles key to FIFA's development programmes - (Link provided)".

Corporate social responsibility (CSR) has been a growing activity undertaken by all types of sport organizations due to the ever increasing interest and desire for people within communities to make sure organizations' business practices are done in a socially acceptable 
behavior (Lewis, 2003; Walker \& Kent, 2009). Although there are some remaining issues as to the way these social activities are conducted, it has the potential to significantly boost sport organizations' global status and restore football fans' trust towards the organization they identify themselves with (Babiak \& Wolfe, 2009; Godfrey, 2009; Lewis, 2003; Walker, Kent, \& Vincent, 2010). One of the issues that have been in the way for sport organizations to fully capitalize on the positive outcomes of CSR activities has been the way the latter communicate these social activities (Douvis, Kyriakis, Kriemadis, \& Vrondou, 2014). For example the "Football for Hope" initiative (launched in 2005) is one of FIFA's many CSR activities which sustains responsible community projects by providing funding, equipment, training, knowhow and exposure which brings hope and opportunities to disadvantaged minorities and improves the lives of young people within these communities (FIFA, 2014). This inevitably contributes towards the achievement of FIFA's mission which is to build a better future. Findings show that FIFA does indeed provide evidence and information about their social developments through football (“\#WorldCup Legacy Fund split: US 60m to infrastructure, 15 to \#womensfootball, 15 to grassroots, 10 to other projects"). However, this maintains the argument that there is a clear lack of interaction between FIFA and its followers.

The four aforementioned types of social media communication (i.e., Informing, Marketing, Personalizing and Activating; Meng et al., 2015) seem interconnected. For example, FIFA tweeted “Thanks@GarethBale11 for your help in trying to reduce the spread of Ebola in affected communities. \#wecanbeatebola" This tweet is a good example of the interrelatedness between all four types of communication. Indeed it informs football fans that FIFA is fully involved in reducing the spread of Ebola in affected communities, in addition it promotes both FIFA's activity and players' involvement towards public health and Ebola which can be confirmed by this tweet "TOGETHER \#WECANBEATEBOLA:Learn about FIFA's public health campaign in the fight against Ebola-(Link provided)". In terms of activating, the first tweet shows that FIFA used the hashtag \#wecanbeatebola which according 
to Lovejoy et al. (2012) signifies that the message is relevant to a particular subject and by using the hashtag it gives organizations the opportunity to also get followers involved. For example, FIFA could encourage football fans to use the \#wecanbeatebola to ask questions and spread the news about FIFA's health efforts.

In terms of personalizing, it shows that FIFA initiates contact by mentioning @GarethBale11. As Lovejoy et al. (2012) argued that through these messages, a conversation is created between an organization and the user, but can also be seen by all other users either following the organization or on the individual's account. This would enable IFs to communicate and focus their messages to fans/followers and so, would involve sharing information on corporate social responsibility including themes such as "Sport development", "Community activities and programs", and "Worldwide issues". CSR information could be communicated more effectively and shared more often by FIFA using multiple communication strategies as one tweet could be used to inform, promote, activate and personalize towards fans/followers. This therefore, emphasizes the gap that needs to be filled by FIFA in order to fully capitalize from the opportunities Twitter offers to sport organizations to engage with football fans.

\section{Managerial and Theoretical Implications}

Maximizing the use of Twitter can contribute towards the achievement IFs' objectives and so it is imperative to develop and sustain this link successfully. This study exposes the opportunities for IFs, through the use of Twitter, to successfully engage and interact with football fans and followers. Even though the study focused on the use of Twitter by FIFA, the outcomes are relevant and directed to IFs in their respective sport.

Originally, football fans use Twitter in order to obtain updated information and news on teams, players, coaches, transfers and other associated features of the organization (Informing). Indeed, by sharing live updates, exclusive news, interviews, pictures and videos, it enables IFs to answer their expectations from appropriate and pertinent information 
therefore enhancing their gratification. Additionally, Twitter provides IFs with valuable opportunities to present their target market to marketing communications in regards to teams, games and events (Marketing). Indeed, by making sure promotion and advertising are related and valued by football fans, IFs can boost ticket and official merchandise sales, and generate a greater audience to their events.

Notwithstanding, there is a potential risk of over-commercializing on Twitter which has become a problem for some organizations and may cause football fans to look away (Meng et al., 2015). Furthermore, Twitter also enables IFs to reach out to football fans by directing them to a whole group of other fans and by asking questions and getting them involved, this generates co-creation and stimulates feedback (Activating). This communication strategy can prove to be successful in producing opportunities for group membership and augmenting what can be called "fan-community" engagement. Moreover, the contact made between IFs and football fans can be personalized with individual fans or a group of fans through directed dialogues (Personalizing). In effect, by further developing the online availability aspect of IFs and building a more "tailor-made" approach, this has the potential to strengthen the relationship with football fans. Finally, Twitter can give IFs the opportunity to communicate and promote most of its activities within the sport they represent. However, communicating activities outside sport such as corporate social responsibility has proven to accelerate football fans' satisfaction, sense of belonging and expand relationships (Social development).

This gives IFs the opportunity to build trust and enhance their global reputation as this feature is interconnected with all four other features within the online communication strategy. Indeed by providing live updates, pictures and videos of the activities (Informing), promoting and exposing football fans to relevant information that can be of value for them (Marketing), getting football fans involved in the development, asking questions and gathering their feedback on potential or current activities (Activating) and personalize contact 
through individual or group discussions (Personalizing), IFs will be able to fulfil their objectives and coagulate their relationship with their football fans, and create a competitive advantage over other IFs.

It is important for IFs to note that whilst one-way communication provides content that appeals to and is wanted by football fans, it will not be as beneficial if two-way communication is neglected which emphasizes the uniqueness of Twitter in that it generates personal contact between organizations and their fans (Meng et al., 2015). Apart from the communication themes that have been discussed throughout this study, there are further recommendations to be made towards IFs who use Twitter. Although there is a risk of getting fans involved in their activity developments through Twitter due to the image IFs, such as FIFA, can have in the eyes of football fans it is really important for the IFs to consider using more interpersonal and activating approaches to communicating on Twitter as this will motivate football fans to engage more frequently and will help IFs strengthen their image by constantly developing their sport, making it available to all through different communities around the globe whilst also giving football fans the opportunity to have an input in developing the sport within their respective communities.

Our research contributes to the understanding of sport organizations' use of social media. Particularly, it is the first study to address IFs' use of social media. It has confirmed Meng et al. (2015) framework of four social media communication strategies and suggested that these are interconnected. CSR activities have been highlighted as a potential message that could be used by IFs in connection with these strategies to build trust and reputation.

\section{Limitations and Further Research}

There are some limitations to the current study. Our research was undertaken during a five month period of a single international sport federation which could be considered a short period of time to draw conclusions on the way IFs use Twitter. Therefore this limits the understanding of how IFs use Twitter by only basing the study on one of the many that are 
involved in sport. Although the time period seemed short, there were a lot of tweets collected which provided a good representation of the content displayed on FIFA's Twitter accounts. It could be argued that other IFs may well be more interactive and use dialogic tweets with their followers rather than mainly using one-way communication. Future research could compare and contrast different IFs' use of Twitter and of other social media platforms in order to determine whether the use and content differs through different sports. In addition to this, a similar study could analyze IFs' online activities in the build up to events, during and after the events they organize or are associated to, such as the FIFA World Cup, the UEFA European Championship or the World Rugby World Cup. Indeed this would be of interest to both determine if the type of content and the type of interaction varies during these international events. Similarly, a study focusing on fans/followers' perceptions of IFs social media engagement through personalizing and activating tweets would revealed the impact of the latter social media strategy.

Greater attention could also have been paid to the frequent use of hashtag by FIFA. Indeed, almost half of FIFA's tweets use hashtag. No research has yet shown the interest or value in using hashtag, but the present research show the importance of such a use in social media. It could be argued that hashtag are used for marketing purpose, and so related to the 'marketing' social media communication strategy. However, further research needs to be undertaken on the topic we would name \#marketing. Particularly, what is the value of \#marketing strategies?

\section{Conclusion}

This research gives a first insight into how one of the most popular social media platforms is being used by one of the most recognizable IFs, FIFA, to communicate with football fans/followers all around the world. Additionally, this research helps understand more generally the use of Twitter by IFs to interact and engage with followers. Moreover, Twitter is seen as one of the best social media platforms to enhance relationships with football fans 
however, there are still unanswered questions on how to best use Twitter in order to interact with organizations' fans on a regular basis. As a meta-organization, FIFA does share information with followers but showed little interaction with them, included the affiliated national football associations. Results suggest FIFA uses more one-way communication, mainly sharing stakeholders' news, rather than using two-way communication, and this represents a missing opportunity to engage with football fans and national football associations in order to rebuild its trust and reputation. 


\section{References}

Abeza, G., O'Reilly, N., \& Reid, I. (2013). Relationship marketing and social media in sport. International Journal of Sport Communication, 6, 120-142. doi:10.1123/ijsc.6.2.120

Abeza, G., O’Reilly, N., \& Seguin, B. (2017). Social media in relationship marketing: The perspective of professional sport managers in the MLB, NBA, NFL, and NHL. Communication \& Sport. 10(3), doi:10.1177/2167479517740343

Abeza, G., O’Reilly, N., Seguin, B., \& Nzindukiyimana, O. (2017). Social media as a relationship marketing tool in professional sport: A netnographical exploration. International Journal of Sport Communication, 10, 325-358. doi:10.1123/ijsc.2017-0041

Ahrne, G., \& Brunsson, N. (2008). Meta-organisations. Cheltenham, UK: Edward Elgar.

Babiak, K., \& Wolfe, R. (2009). Determinants of corporate social responsibility in professional sport: Internal and external factors. Journal of Sport Management, 23(6), 717-742. doi:10.1123/jsm.23.6.717

BBC News. (2015). FIFA corruption crisis: Key questions answered. Retrieved from https://www.bbc.com/news/world-europe-32897066

Bortree, D., \& Seltzer, T. (2009). Dialogic strategies and outcomes: An analysis of environmental advocacy groups' Facebook profiles. Public Relations Review, 35(3), 317-319. doi:10.1016/j.pubrev.2009.05.002

Bruhn, M., Schoenmueller, V., \& Schaefer, D.B. (2012) Are social media replacing traditional media in terms of brand equity creation? Management Research Review, 35(9), 770790. doi:10.1108/01409171211255948

Campos, C., Anagnostopoulos, C., \& Chadwick, S. (2013). Assessing the integration of Twitter into the strategic operations of sporting organisations, Choregia, 9(1), 43-66. 
Cleland, J. A. (2010). From passive to active: The changing relationship between supporters and football clubs. Soccer \& Society, 11(5), 537-552. doi:10.1080/14660970.2010.497348

Douvis, J., Kyriakis, V., Kriemadis, T., \& Vrondou, O. (2014). How do Greek sport organizations promote and communicate their corporate social responsibility (CSR) efforts? Gymnasium: Scientific Journal of Education, Sports \& Health, 15(1), 52-60.

Eagleman, A. N. (2013). Acceptance, motivations, and usage of social media as a marketing communications tool amongst employees of sport national governing bodies. Sport Management Review, 16(4), 488-497. doi:10.1016/j.smr.2013.03.004

FIFA. (2014). Activity report 2013. 64 ${ }^{\text {th }}$ FIFA Congress, São Paulo, 10-11 June 2014. Retrieved from https://resources.fifa.com/image/upload/fifa-activity-report-20132338789.pdf?cloudid=wpf547zsib0wbsolmev6

FIFA. (2016). FIFA statutes. Retrieved from https://resources.fifa.com/mm/document/affederation/generic/02/78/29/07/fifastatutsw eben_neutral.pdf

FIFA. (2018a). How FIFA works. Retrieved from https://www.fifa.com/about-fifa/who-weare

FIFA. (2018b). Fans drive record digital interest in FIFA world cup. Retrieved from https://www.fifa.com/worldcup/news/fans-drive-record-digital-interest-in-fifa-worldcup

Filo, K., Lock, D., \& Karg, A. (2015). Sport and social media research: A review. Sport Management Review, 18(2), 166-181. doi:10.1016/j.smr.2014.11.001

Forbes. (2017). Live MLB games begin streaming to Twitter on tuesdays, comes on heels of Facebook deal. Retrieved from https://www.forbes.com/sites/maurybrown/2017 /05/25/live-mlb-games-begin-streaming-to-twitter-on-tuesdays-comes-on-heels-offacebook-deal/\#2e14460d5f0d 
Forster, J. (2006). Global sports organisations and their governance. Corporate Governance. $6(1), 72-83$.

Frederick, E., Lim, C. H., Clavio, G., Pedersen, P. M., \& Burch, L. M. (2014). Choosing between the one-way or two-way street: An exploration of relationship promotion by professional athletes on Twitter. Communication \& Sport, 2(1), 80-99. doi:10.1177/2167479512466387

Gibbs, C., O'Reilly, N., \& Brunette, M. (2014). Professional team sport and Twitter: Gratifications sought and obtained by followers. International Journal of Sport Communication, 7, 188-213. doi:10.1123/IJSC.2014-0005

Gillooly, L., Anagnostopoulos, C., \& Chadwick, S. (2017). Social media-based sponsorship activation-A typology of content. Sport, Business and Management: An International Journal, 7(3), 293-314. doi:10.1108/SBM-04-2016-0016

Godfrey, P. C. (2009). Corporate social responsibility in sport: An overview and key issues. Journal of Sport Management, 23(6), 698-716. doi:10.1123/jsm.23.6.698

Grönroos, C. (2004). The relationship marketing process: Communication, interaction, dialogue, value. Journal of Business \& Industrial Marketing, 19(2), 99-113. doi:10.1108/08858620410523981

Hambrick, M. E. (2012). Six degrees of information: Using social network analysis to explore the spread of information within sport social networks. International Journal of Sport Communication, 5, 16-34. doi:10.1123/ijsc.5.1.16

Hambrick, M. E., \& Kang, S. J. (2015). Pin it: Exploring how professional sports organizations use Pinterest as a communications and relationship-marketing tool. Communication \& Sport, 3(4), 434-457. doi:10.1177/2167479513518044

Hambrick, M. E., Simmons, M. J., Greenhalgh, P. G., \& Greenwell, T. C. (2010). Understanding professional athletes' use of Twitter: A content analysis of athlete 
tweets. International Journal of Sport Communication, 3, 454-471.

doi:10.1123/ijsc.3.4.454

Jordan, T., Upright, P., \& Forsythe, S. A. (2017). Social media and relationship marketing in community sport. KAHPERD Journal, 55(1), 8-19.

Lebel, K., \& Danylchuk, K. (2014). Facing off on Twitter: A generation Y interpretation of professional athlete profile pictures. International Journal of Sport Communication, 7, 317-336. doi:10.1123/IJSC.2014-0004

Lewis, S., (2003). Reputation and corporate responsibility. Journal of Communication Management, 7(4), 356-366. doi:10.1108/13632540310807494

López-González, H., Stavros, C., \& Smith, A. C. (2017). Broadcasting sport: Analogue markets and digital rights. International Communication Gazette, 79(2), 175-189. doi:10.1177/1748048517694969

Lovejoy, K., Waters, R.D., \& Saxton, G.D. (2012). Engaging stakeholders through Twitter: How nonprofit organizations are getting more out of 140 characters or less. Public Relations Review, 38(2), 313-318. doi:10.1016/j.pubrev.2012.01.005

MacIntosh, E., Abeza, G., \& Lee, J. (2017). Enriching identity in the "fan nation": The role of social media in the case of a professional sport team. Sport, Business and Management: An International Journal, 7(3), 315-331. doi:10.1108/SBM-06-20160028

Mahan, J.E. (2011). Examining the predictors of consumer response to sport marketing via digital social media. Sport Management and Marketing, 9(3-4), 254-267. doi:10.1504/IJSMM.2011.041575

Malcourant, E., Vas, A., \& Zintz, T. (2015). World anti-doping agency: A metaorganizational perspective. Sport, Business and Management: An International Journal, 5(5), 451-471. doi:10.1108/SBM-03-2015-0012 
McLean, R., \& Wainwright, D. (2009) Social networks, football fans, fantasy and reality How corporate and media interests are invading our lifeworld. Journal of Information, Communication and Ethics in Society, 7(1), 54-71. doi:10.1108/14779960910938098

Meng, M. D., Stavros, C., \& Westberg, K. (2015). Engaging fans through social media: implications for team identification. Sport, Business and Management: An International Journal, 5(3), 199-217. doi:10.1108/SBM-06-2013-0013

Naraine, M. L., \& Parent, M. M. (2016a). Illuminating centralized users in the social media ego network of two national sport organizations. Journal of Sport Management, 30(6), 689-701. doi:10.1123/jsm.2016-0067

Naraine, M. L., \& Parent, M. M. (2016b). "Birds of a feather": An institutional approach to canadian national sport organizations' social-media use. International Journal of Sport Communication, 9, 140-162. doi:10.1123/ijsc.2016-0010

Naraine, M. L., \& Parent, M. M. (2017). This is how we do it: A qualitative approach to national sport organizations' social-media implementation. International Journal of Sport Communication, 10, 196-217. doi:10.1123/IJSC.2017-0006

NFL Media. (2016). National football league and Twitter announce streaming partnership for thursday night football. Retrieved from https://nflcommunications.com/Documents/2016\%20Releases/NFL\%20TWTR\%20T NF.pdf

Nicholson, M., Kerr, A., \& Sherwood, M. (2015). Sport and the media. Managing the nexus. Oxford, UK: Elsevier.

O'Shea, M., \& Alonso, A.D. (2011). Opportunity or obstacle? A preliminary study of professional sport organisations in the age of social media. International Journal of Sport Management and Marketing, 10(3/4), 196-212.

doi:10.1504/IJSMM.2011.044790 
Parganas, P., Anagnostopoulos, C., \& Chadwick, S. (2015). 'You'll never tweet alone': Managing sports brands through social media. Journal of Brand Management, 22(7), $551-568$.

Parganas, P., Anagnostopoulos, C., \& Chadwick, S. (2017). Effects of social media interactions on brand associations: A comparative study of soccer fan clubs. International Journal of Sports Marketing and Sponsorship, 18(2), 149-165. doi:10.1108/IJSMS-05-2017-087

Persson R.H.T. (2008). Social capital and social responsibility in Denmark more than gaining public trust. International Review for the Sociology of Sport, 43(1), 35-51. doi:10.1177/1012690208094655

Persson R.H.T. (2011). Good governance and the danish football association: Between international and domestic sport governance. International Journal of Sport Policy and Politics, 3(3), 373-384. doi:10.1080/19406940.2011.596154

PGA Tour (2017). PGA tour renews agreement with Twitter as global live streaming distribution platform for PGA TOUR LIVE OTT coverage in 2018. Retrieved from https://www.pgatour.com/company/2017/09/26/pga-tour-renews-agreement-withtwitter-as-global-live-streaming-.html

Pritchard, M.P., Stinson, J., \& Patton, E. (2010). Affinity and affiliation: The dual-carriage way to team identification. Sport Marketing Quarterly, 19(2), 67-77.

Purdue, D. (2001). Neighbourhood governance: Leadership, trust and social capital. Urban Studies, 38(12), 2211-2224. doi:10.1080/00420980120087135

Smith, N. A., Fischer, E., \& Youngjian, C. (2012). How does brand-related user-generated content differ across YouTube, Facebook, and Twitter? Journal of Interactive Marketing, 26(2), 102-113. doi:10.1016/j.intmar.2012.01.002 
Statista. (2018). Number of social network users worldwide from 2010 to 2021 (in billions). Retrieved from https://www.statista.com/statistics/278414/number-of-worldwidesocial-network-users/

Stavros, C., Meng, D. M., \& Westberg, K. (2014). Understanding fan motivation for interacting on social media. Sport Management Review, 17(4), 455-469. doi:10.1016/j.smr.2013.11.004

Sutton, W., McDonald, M., Milne, G., \& Cimperman, J. (1997). Creating and fostering fan identification in professional sports. Sport Marketing Quarterly, 6(1), 15-22.

Walker, M., \& Kent, A. (2009). Do fans care? Assessing the influence of corporate social responsibility on consumer attitudes in the sport industry. Journal of Sport Management, 23(6), 743-769. doi:10.1123/jsm.23.6.743

Walker, M., Kent, A., \& Vincent, J. (2010). Communicating socially responsible initiatives: An analysis of U.S. professional teams. Sport Marketing Quarterly, 19(4), 187-195.

Wallace, L., Wilson, J., \& Miloch, K. (2011). Sporting facebook: A content analysis of NCAA organizational sport pages and big 12 conference athletic department pages. International Journal of Sport Communication, 4, 422-444. doi:10.1123/ijsc.4.4.422

Waters, R.D., \& Jamal, J.Y. (2011). Tweet, tweet, tweet: A content analysis of nonprofit organizations' Twitter updates. Public Relations Review. 37, 321-324. doi:10.1123/ijsc.4.4.422

Waters, R.D., Burnett, E., Lamm, A., \& Lucas, J. (2009). Engaging stakeholders through social networking: How nonprofit organizations are using Facebook. Public Relations Review, 35(2), 102-106. doi:10.1016/j.pubrev.2009.01.006

Williams, J., \& Chinn, S. J. (2010). Meeting relationship-marketing goals through social media: A conceptual model for sport marketers. International Journal of Sport Communication, 3, 422-437. doi:10.1123/ijsc.3.4.422 
Winand, M., Scheerder, J., Vos, S., \& Zintz, T. (2016). Do non-profit sport organisations innovate? Types and preferences of service innovation within regional sport federations. Innovation, 18(3), 289-308. doi:10.1080/14479338.2016.1235985

Winand, M., Vos, S., Zintz, T., \& Scheerder, J. (2013). Determinants of service innovation: A typology of sports federations. International Journal of Sport Management and Marketing, 13(1/2), 55-73. doi:10.1504/IJSMM.2013.055194

Witkemper, C., Hoon Lim, C., \& Waldburger, A. (2012). Social media and sports marketing: Examining the motivations and constraints of Twitter users. Sport Marketing Quarterly, 21(3), 170-18.

Yin, R. (2003). Case study research: Design and methods. Thousand Oaks, CA: Sage.

Zintz, T., \& Winand, M. (2013). Les fédérations sportives. [Sport federations] Courrier hebdomadaire du CRISP, 2179, 5-52. 
Table 1. FIFA Twitter communication content by themes and coverage

\begin{tabular}{|c|c|c|c|}
\hline Themes & Sub-themes & Number of tweets & Coverage $(\%)$ \\
\hline \multirow[t]{5}{*}{ Informing } & & 4814 & 89.33 \\
\hline & Activities outside sport & 345 & 7.17 \\
\hline & Diversion & 1055 & 21.91 \\
\hline & Organizational News & 453 & 9.41 \\
\hline & Stakeholder News & 2961 & 61.51 \\
\hline \multirow[t]{3}{*}{ Marketing } & & 521 & 9.67 \\
\hline & Direct Sales & 70 & 13.43 \\
\hline & Promotion & 451 & 86.73 \\
\hline \multirow[t]{3}{*}{ Activating } & & 483 & 8.96 \\
\hline & Gathering feedback & 1 & 0,21 \\
\hline & Group involvement & 482 & 99,8 \\
\hline \multirow[t]{3}{*}{ Personalizing } & & 57 & 1.06 \\
\hline & Direct responses & 2 & 3.51 \\
\hline & Initiating contact & 55 & 96.5 \\
\hline
\end{tabular}

Note. Tweets may have been categorized in more than one theme so that the total coverage exceeds $100 \%$. 
Table 2. FIFA Twitter communication content by themes

\begin{tabular}{|c|c|}
\hline \multirow{2}{*}{$\begin{array}{ll} & \text { Themes } \\
\text { Informing } & \end{array}$} & Examples of tweet \\
\hline & \\
\hline $\begin{array}{l}\text { Activities outside sport } \\
\text { Information related to players, } \\
\text { staff, or the organization } \\
\text { participating in non-sport } \\
\text { related activities. }\end{array}$ & $\begin{array}{l}\text { "Happy birthday to@YCabayeofficiel (29), Leonardo } \\
\text { Cuellar(63)\&@JessFishlock (28)" } \\
\text { "FIFA statement on the Ebola epidemic: (Link } \\
\text { provided)" }\end{array}$ \\
\hline $\begin{array}{l}\text { Diversion } \\
\text { Diverting followers to other } \\
\text { content including pictures, } \\
\text { blogs or websites, match } \\
\text { reports, videos, interviews and } \\
\text { stats from players, coaches and } \\
\text { members of staff from FIFA. }\end{array}$ & $\begin{array}{l}\text { "VIDEO: Take a closer look@FIFATMS \& how the } \\
\text { International Transfer Matching System works. } \\
\text { \#transferwindow: (Link provided)" } \\
\text { "Report \& pics from Korea Republic's 2-0win over } \\
\text { Uzbekistan in the@AFCAsianCup last eight: (Link } \\
\text { provided)" } \\
\text { "EXCLUSIVE: We chat to@salomonkalou on } \\
@ \text { @IFCI_tweet, \#AFCON2015 \& the absence of } \\
@ \text { didierdrogba: (Link provided)" } \\
\text { "STATS: @Cristiano, @Socceroos, } \\
@ \text { SouthamptonFC, Diego Alves \& Francesco Totti } \\
\text { star this week: (Link provided) }\end{array}$ \\
\hline $\begin{array}{l}\text { Organizational News } \\
\text { News and information directly } \\
\text { associated with the } \\
\text { organization in relation to the } \\
\text { sport of football. }\end{array}$ & $\begin{array}{l}\text { "RT@jeromevalcke: Event dates for \#confeds in } 2017 \\
\& 2018 \text { \#WorldCup scheduled to be announced in } \\
\text { Morocco after FIFA Executive Committee mee..." } \\
\text { "\#WorldCup Legacy Fund split: US } 60 \mathrm{~m} \text { to } \\
\text { infrastructure, } 15 \text { to \#womensfootball, } 15 \text { to } \\
\text { grassroots, } 10 \text { to other projects." } \\
\text { "Key sustainability achievements of \#WorldCup } \\
\text { included carbon offsetting \& support for } 26 \\
\text { community projects. (1/2)" } \\
\text { "18.2\% tickets sold at a discounted rate, } 445 \text { tonnes } \\
\text { of waste recycled, US } 2.25 \text { morth of IT equipment } \\
\text { donated. }(2 / 2) "\end{array}$ \\
\hline $\begin{array}{l}\text { Stakeholder News } \\
\text { News and information directly } \\
\text { associated with the teams, } \\
\text { players, members of staff at } \\
\text { FIFA, clubs/National teams } \\
\text { and other international leagues } \\
\text { in relation to the sport of } \\
\text { football. }\end{array}$ & $\begin{array}{l}\text { "RT@SeppBlatter: Good Luck@AAucklandCity_FC\& } \\
@ \text { Moghreb_Tetouan tonight in the 1st game of the } \\
2014 \text { \#ClubWC." } \\
\text { "Messi strike earns cup advantage over @Atleti } \\
\text { @FCBarcelona." } \\
\text { "Rodgers buoyed by Sterling-inspired@LFC } \\
\text { \#LeagueCup." } \\
\text { "@OfficialASRoma target tenth title, @acffiorentina } \\
\text { face@Atalanta_BC in \#CoppaItalia." } \\
\text { "LIVE: @LesVerts - @BafanaBafana kick-off in } \\
\text { 2nd GroupC match of the day \#AFCON2015: (Link } \\
\text { provided)" }\end{array}$ \\
\hline
\end{tabular}


Table 2. FIFA Twitter communication content by themes (continued)

\begin{tabular}{|c|c|}
\hline Themes & Examples of tweet \\
\hline \multicolumn{2}{|l|}{ Marketing } \\
\hline $\begin{array}{l}\text { Direct Sales } \\
\text { Providing fans with the } \\
\text { opportunity to easily purchase } \\
\text { items online, such as tickets and } \\
\text { official merchandise. }\end{array}$ & $\begin{array}{l}\text { "Want something other than socks? Get what you } \\
\text { really wanted at the Official FIFA Online Store: (Link } \\
\text { provided)" } \\
\text { "@Cruz_Azul_FC fans, ready for Morocco 2014? } \\
\text { Get your\#ClubWC tickets today!: (Link provided)" }\end{array}$ \\
\hline $\begin{array}{l}\text { Promotion } \\
\text { Providing relevant marketing } \\
\text { communications through } \\
\text { advertising or promotion of the } \\
\text { teams, games, competitions, } \\
\text { special events, live league } \\
\text { games but also international } \\
\text { games all around the world, } \\
\text { upcoming league, domestic cup, } \\
\text { Champions league from } \\
\text { different continents, and } \\
\text { international games. }\end{array}$ & $\begin{array}{l}\text { “\#BallondOr: @Cristiano, Messi or } \\
\text { @Manuel_Neuer? } \\
\text { We'll find out in less than } 24 \text { hours!” } \\
\text { "LIVE: @stokecity 0-1 @ @ chelseafc at HT. Follow the } \\
\text { rest of the @premierleague clash here: (Link } \\
\text { provided)" } \\
\text { "Preview the rest of the weekend's @LaLiga games } \\
\text { with@FCBarcelona visiting Getafe: (Link } \\
\text { provided)" }\end{array}$ \\
\hline Activating & \\
\hline $\begin{array}{l}\text { Gathering feedback } \\
\text { Collect fan/followers' opinions } \\
\text { before developing or } \\
\text { implementing a new idea. }\end{array}$ & $\begin{array}{l}\text { "RT@FIFAWWC: YOUR VIEW: \#U20WWC is over; } \\
\text { but YOUR participation is not! How can we improve } \\
\text { our content? We'd love your feedback." }\end{array}$ \\
\hline $\begin{array}{l}\text { Group involvement } \\
\text { Ensure, where possible, fans are } \\
\text { included in relevant general } \\
\text { interactive processes. Can also } \\
\text { include group discussions. }\end{array}$ & $\begin{array}{l}\text { "Question: Which team impressed you most in the } \\
\text { weekend's @UEFAEURO qualifiers, and why?" } \\
\text { "RT Best @UEFAEURO performance: } \\
\text { @ArranInYYC Wales, they showed a lot of } \\
\text { determination to hold Belgium to a draw away." }\end{array}$ \\
\hline Personal & \\
\hline $\begin{array}{l}\text { Direct responses } \\
\text { Directly responding to } \\
\text { individual questions or } \\
\text { comments. } \\
\end{array}$ & $\begin{array}{l}\text { “RT@PetrCech: @FIFAcom yes, of course :-)” } \\
\text { "RT @acciesfc: @FIFAcom Many thanks FIFA, } \\
\text { recognising our great run!” }\end{array}$ \\
\hline $\begin{array}{l}\text { Initiating contact } \\
\text { Direct, interpersonal contact } \\
\text { with an individual fan/follower, } \\
\text { initiated by the organization. }\end{array}$ & $\begin{array}{l}\text { "Thanks@GarethBale11 for your help in trying to } \\
\text { reduce the spread of Ebola in affected communities. } \\
\text { \#wecanbeatebola." } \\
\text { "@SanLorenzo fans, think your club can lift another } \\
\text { trophy in December? \#ClubWC tickets here: (Link } \\
\text { provided)" } \\
\text { "RT@arangelz: @FIFAcom have no favourites but I } \\
\text { think@Cristiano will win it." }\end{array}$ \\
\hline
\end{tabular}

